\title{
IMPACT OF A PHARMACIST-LED PATIENT EDUCATION INITIATIVE ON GLYCEMIC CONTROL OF PATIENTS WITH TYPE 2 DIABETES MELLITUS: A SINGLE-CENTER EXPERIENCE IN WEST JAKARTA, INDONESIA
}

\author{
RANI SAURIASARI*, RIDHO MUHAMMAD SAKTI \\ Faculty of Pharmacy, Universitas Indonesia, Depok, 16424, Indonesia. Email: rani@farmasi.ui.ac.id \\ Received: 25 May 2018, Revised and Accepted: 30 September 2018
}

ABSTRACT

Objective: This study aimed to evaluate the effect of the provision of drug-related information and patient education booklets on the hemoglobin A1c (HbA1c) levels of patients with type 2 diabetes mellitus.

Methods: This prospective study was conducted at the Kembangan Health Center, West Jakarta, Indonesia, from March to June 2017. A total of 30 patients were divided into two equal groups: In addition to routine treatment, patients in the intervention group received drug-related information and patient education booklet, while those in the control group received no additional intervention. The provision of drug information was through direct education as well as through telephone, short messages, and booklet. HbA1c level was measured as a surrogate measure of treatment adherence. HbA1c concentration was measured at baseline and 11 weeks after the intervention.

Results: Mean HbA1c level in the intervention group decreased from $8.05 \pm 0.91 \%$ at week 0 to $6.92 \pm 0.47 \%$ at week 11 after intervention (p<0.05).

Conclusion: In this study, provision of drug information and patient education booklets helped to improve the patient compliance.

Keywords: Hemoglobin A1c, Patient adherence, Type 2 diabetes mellitus, Drug information, Booklet, Pharmacist.

(C) 2018 The Authors. Published by Innovare Academic Sciences Pvt Ltd. This is an open access article under the CC BY license (http://creativecommons. org/licenses/by/4. 0/) DOI: http://dx.doi.org/10.22159/ijap.2018.v10s1.56

\section{INTRODUCTION}

Diabetes mellitus (DM) is a metabolic disorder characterized by high blood glucose levels caused by insufficient insulin. According to the International Diabetes Federation [1], the global prevalence of DM in 2014 was $8.3 \%$, which corresponded to a caseload of 387 million patients. Globally, Indonesia has the seventh highest incidence of DM in the world after China, India, United States, Brazil, Russia, and Mexico. The estimated number of diabetic patients in Indonesia is 8.5 million [1].

DM necessitates long-term treatment which is typically complex. The treatment cost increases by 2-3.5 times in patients who develop complications. Optimal treatment compliance helps prevent disease progression. Poor disease management and low adherence lead to poor drug efficacy [2]. Monitoring of hemoglobin A1c (HbA1c) levels every 3 months helps monitor glycemic control to ensure treatment efficacy. High level of HbA1c reflects poor diabetic control owing to low adherence to treatment [3].

Education of patients about the management of DM was shown to lower the HbA1c level by $0.3-0.76 \%[4,5]$. The purpose of this study was to assess the impact of pharmacist-led provision of drug-related information and patient education on treatment adherence by patients to achieve successful therapy. Insights gained from this study may help to improve the quality of life of patients with type 2 DM during management treatment and help improve the role of pharmacists in health service sector in Indonesia.

\section{METHODS}

Study design and subjects

This prospective study was conducted at a Health Center in the Kembangan District of West Jakarta from March to June 2017. The study protocol was approved by the Ethical Committee for Health Study at the Faculty of Medicine of Universitas Indonesia before the start of the study. The study population comprised of 30 patients with type $2 \mathrm{DM}$ who were prescribed oral antidiabetic drugs. Patients were divided into two groups: Intervention group received drug information and booklet, while the control group did not receive drug information and booklet. Each group consisted of 15 patients according to the total minimum sample [6]. The inclusion criteria were as follows: Patients aged $>35$ years who were diagnosed with type $2 \mathrm{DM}$ at least 3 months before the start of the study. Patients who were receiving medicines such as birth control pills and herbal medicine and those on insulin therapy were excluded from the study. Patients in the intervention group received drug-related information at the time of dispensing of medicine by pharmacist as well as through phone call, short message service (SMS), and booklet. HbA1c levels were measured as a surrogate measure of patient adherence using Afinion $^{\mathrm{m}}{ }^{\mathrm{m}}$ AS100 Analyzer.

Materials used to collect data in this study were questionnaire and booklet [7]. The questionnaire consisted of a list of questions against which a respondent was required to indicate his response by means of a check $(\sqrt{ })$ mark in the available column; a space for short answers was also available for each question. Booklet used in this study was prepared by Puspitasari [8] and modified by Yuniarti [9] for patients with type $2 \mathrm{DM}$ in Depok. The information in the booklet was provided in a manner that was easy to understand by an average patient. Information in the booklet included the types of DM, normal blood glucose level, symptoms, complications, medications, management, signs of hypoglycemia, routine monitoring, prevention, and management of diabetic foot.

Samples collection

Sample collection method used in this study was consecutive sampling method. During data collection pre- and post-intervention, the sample 
of capillary blood was collected from all subjects by finger prick to measure the HbA1c level. The flow chart for group allocation and attrition among the subjects is found in Fig. 1.

\section{Statistical analysis}

Univariate analysis was used for descriptive data. Between-group differences were assessed using t-test. Distribution of variables was assessed using Shapiro-Wilk, and the bivariate analysis was performed according to the data distribution result. $\mathrm{p}<0.05$ were considered to be statistically significant difference. All analyses were performed on SPSS version 20 (IBM Corp., USA).

\section{RESULTS}

\section{Study subject characteristic}

Demographic and anthropometric characteristics of the patients are presented in Table 1, whereas clinical characteristics are presented in Table 2.

No significant difference was observed between the two groups with respect to the proportion of male and female patients. Basic Health

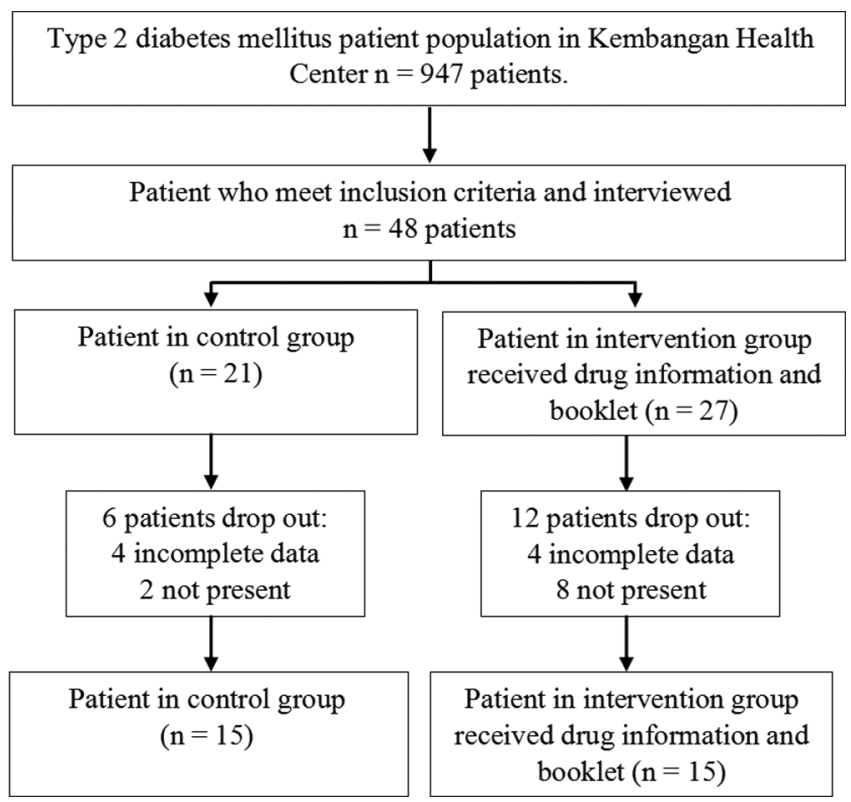

Fig. 1: Schematic illustration of the study design and patient-selection criteria
Research results showed that the prevalence of DM among women is higher than that in men [10]. This is consistent with the study by Irawan [11] which showed that the higher prevalence of DM in women is attributable to a higher risk of increase in body mass index (BMI) due to premenstrual syndrome which leads to accumulation of body fat [12].

No significant between-group difference was observed with respect to the age of patients $(p=0.713)$ [13]. The average BMI in the two groups also showed no significant difference $(p=0.856)$ [14]. However, a significant difference was observed with respect to education level of patients between the two groups $(\mathrm{p}=0.048)$. Individuals with high education level tend to be more aware and health conscious. The result was similar with the study of Presetiawati [15] which found that education level affects patient's adherence to medication. However, there was no significant between-group difference with respect to employment status.

No significant between-group difference was observed with respect to baseline FPG, 2-h PPG, systolic BP, diastolic BP, or duration of DM.

We also did not find a significant difference with respect to the number of oral antihyperglycemic drugs prescribed. Most patients in this study received a combination of two oral antidiabetic drugs such as metformin and acarbose. The two groups were also comparable with respect to drug dosage, form, and use of drugs for other conditions. Other drugs prescribed in this study population including simvastatin, bisoprolol, and valsartan did not affect HbA1c value. The intervention in this study for the patients did not improvise patients' knowledge on the side effect of the drugs. There were no correlation intervention group events of side effects. Flatulent was the most common side effect in this study population [16]. Keban reported that $70 \%$ of patients who receive acarbose developed diarrhea, nausea, vomiting, and flatulence [17]. According to Waspadji, flatulent was found in $50 \%$ of $\alpha$-glycosidase inhibitor user [18]. A patient aged 63 years consumed metformin and glibenclamide had complaint of shaking and cold sweat which was a sign of hypoglycemia. Most likely, the hypoglycemia occurs caused by glibenclamide usage.

\section{Correlation with HbA1c level}

Type 2 DM patient's adherence towards HbA1c value after given drug information and booklet

At the beginning of the study, the average HbA1c in the intervention group was $8.05 \pm 0.91 \%$. After receiving drug-related information and booklet (week 11), the average HbA1c level in the intervention group decreased to $6.92 \pm 0.47 \%$, which corresponds to a decrease of $1.13 \pm 0.62 \%$ from the baseline value. In a study by Puspitasari in

Table 1: Demographic and anthropometric characteristics of patients

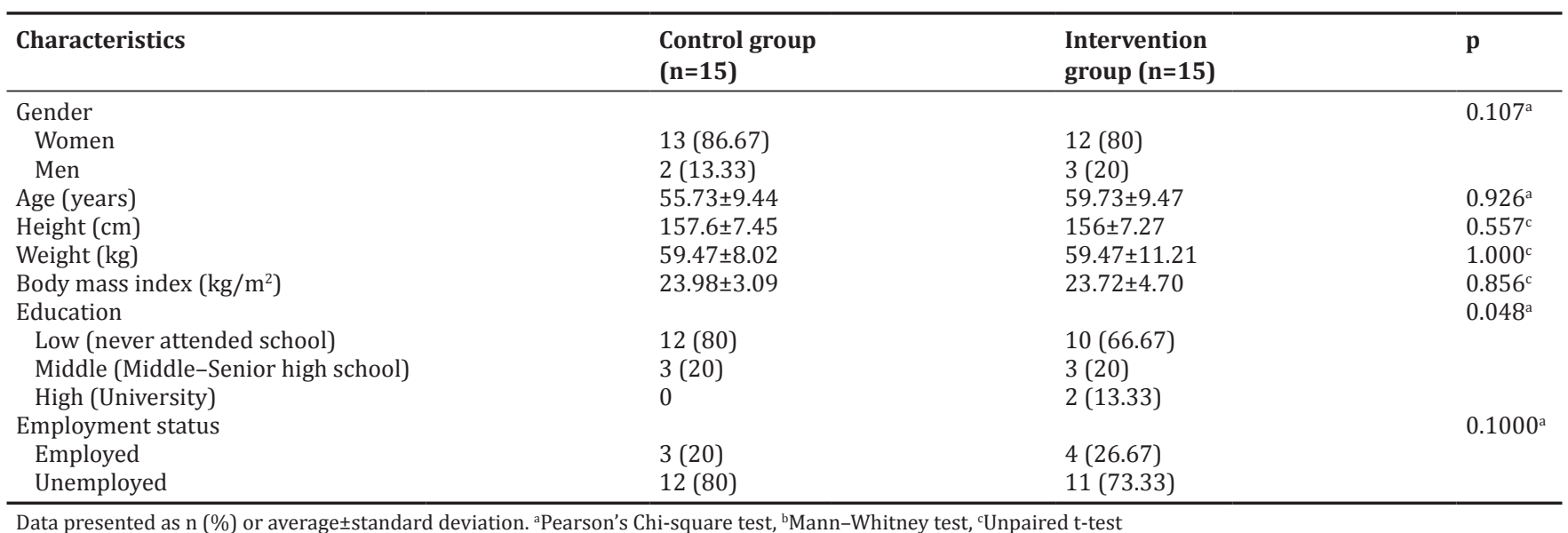


Depok, provision of drug information booklet to diabetic patients decreased HbA1c value by $1.6 \pm 0.55 \%[8,16]$. Another study by Keban revealed that provision of counseling by pharmacist may also reduce $\mathrm{HbA} 1 \mathrm{c}$ value (decrease of $1.76 \pm 0.24 \%$ ) [17]. In the control group, the average HbA1c level at baseline was $7.40 \pm 0.96 \%$ which showed a slight increase to $7.50 \pm 0.97 \%$ at week 11 . The betweengroup difference with respect to the decrease in HbA1c level was statistically significant (paired t-test; $p=0.001$ ). The decrease of HbA1c value was found $40 \%$ in control group and $93.33 \%$ in the intervention group $[19,20]$. These findings imply that provision of drug-related information and booklet to type 2 DM helped to improve patients' adherence as reflected by the decrease in HbA1c level (Figs. 2 and 3, Tables 3-5).

\section{DISCUSSION}

This study indicates that pharmacists can play a key role in improving treatment compliance among patients with type 2 DM by interventions, such as provision of drug information, booklet, and follow-up reminders through SMS. Our findings are consistent with those of a study by Puspitasari [8]. We believe that providing drug information and patient education booklet in this intervention was a complete combination. Patient education about diabetes and the treatment has been shown to improve glycemic control, reduce the risk of hypoglycemia, and reduce treatment cost [21]. Involvement of pharmacists plays a vital role in the management of therapy and helps to improve the clinical outcomes [22]. Provision information related to drugs and other

Table 2: Baseline clinical characteristics of study subjects

\begin{tabular}{|c|c|c|c|}
\hline Characteristic & $\begin{array}{l}\text { Control group } \\
(n=15)\end{array}$ & $\begin{array}{l}\text { Intervention group } \\
(\mathrm{n}=15)\end{array}$ & $\mathbf{p}$ \\
\hline Fasting blood glucose (mg/dL) & $174.53 \pm 58.94$ & $164.60 \pm 48.01$ & $0.561^{\mathrm{a}}$ \\
\hline $2 \mathrm{~h}$ postprandial blood glucose $(\mathrm{mg} / \mathrm{dL})$ & $255.00 \pm 89.44$ & $263.53 \pm 65.39$ & $0.384^{\mathrm{a}}$ \\
\hline \multicolumn{4}{|l|}{ Blood pressure } \\
\hline Systolic (mmHg) & $122.67 \pm 11.00$ & $126 \pm 6.32$ & $0.432^{\mathrm{a}}$ \\
\hline Diastolic (mmHg) & $77.33 \pm 9.61$ & $82.67 \pm 5.93$ & 0.129 \\
\hline \multicolumn{3}{|l|}{ DM duration (Years) } & $0.338^{\mathrm{b}}$ \\
\hline$<1$ & $2(13.33)$ & $4(26.67)$ & \\
\hline $1-5$ & $8(53.33)$ & $6(40)$ & \\
\hline$>5$ & $5(33.33)$ & $5(33.33)$ & \\
\hline \multicolumn{3}{|l|}{ Concurrent disease } & $0.099^{\mathrm{b}}$ \\
\hline Present & $12(80)$ & $13(86.67)$ & \\
\hline Absent & $3(20)$ & $2(13.33)$ & \\
\hline \multicolumn{3}{|l|}{ Total antidiabetic oral (Types) } & $0.830^{\mathrm{b}}$ \\
\hline 1 & $1(6.67)$ & $1(6.67)$ & \\
\hline 2 & $12(80)$ & $13(86.67)$ & \\
\hline 3 & $2(13.33)$ & $1(6.67)$ & \\
\hline \multicolumn{3}{|l|}{ Drug usage } & $0.690^{\mathrm{b}}$ \\
\hline Appropriate & $10(66.67)$ & $11(73.33)$ & \\
\hline Inappropriate & $5(33.33)$ & $4(26.67)$ & \\
\hline \multicolumn{3}{|l|}{ Other drug prescribed } & $0.666^{\mathrm{b}}$ \\
\hline Yes & $11(73.33)$ & $12(80)$ & \\
\hline No & $4(26.67)$ & $3(20)$ & \\
\hline \multicolumn{3}{|l|}{ Side effects } & $0.690^{\mathrm{b}}$ \\
\hline Yes & $4(26.67)$ & $5(33.33)$ & \\
\hline No & $10(66.67)$ & $9(60)$ & \\
\hline
\end{tabular}

Data presented as n (\%) or average \pm standard deviation. ${ }^{a}$ Mann-Whitney test, ${ }^{b}$ Pearson's Chi-squared test, DM: Diabetes mellitus

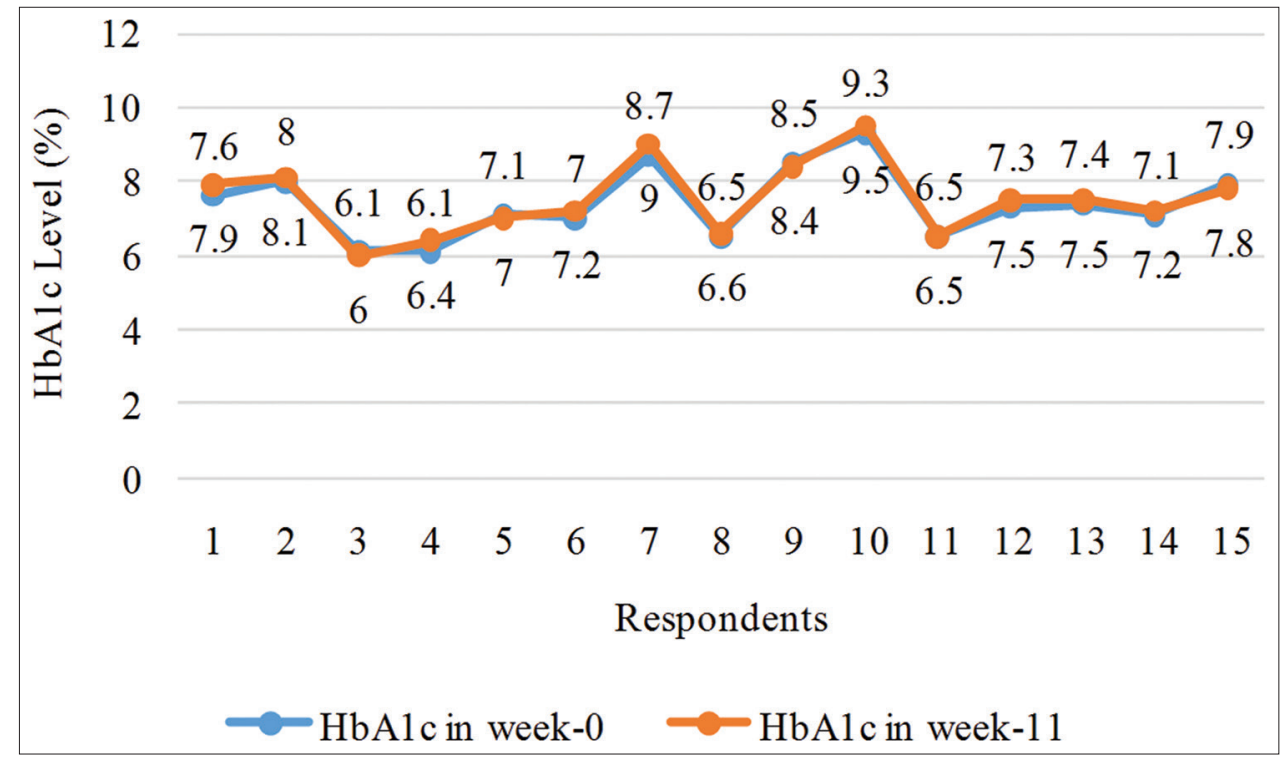

Fig. 2: Pre- and post-intervention hemoglobin A1c level of individual patients in the control group 
aspects of treatment boosts self-efficacy and improves quality of life and BMI of diabetic patients [23]. However, the education material should be tailored according to the patients' condition.

Therefore, drug information and booklet are effective interventions to increase patient adherence. Suppapitiporn et al. found that pharmacist consultation during each visit can increase the effectiveness of blood glucose control program [24]. As against random blood glucose test, HbA1c levels are not affected by short-term changes in blood glucose levels caused by eating, exercise, or intake of medicines. The average HbA1c level among patients in Kembangan Health Center

Table 3: The average difference between HbA1c levels at week 0 and week 11 in each study group

\begin{tabular}{llllc}
\hline \multirow{2}{*}{ Group } & \multicolumn{2}{c}{ Average \pm SD (\%) } & Delta & p \\
\cline { 2 - 3 } & Week-0 & Week-11 & & \\
\hline Control $(\mathrm{n}=15)$ & $7.40 \pm 0.96$ & $7.50 \pm 0.97$ & $-0.1 \pm 0.01$ & $0.653^{\mathrm{a}}$ \\
Intervention (n=15) & $8.05 \pm 0.91$ & $6.92 \pm 0.47$ & $1.13 \pm 0.62$ & $0.000^{\mathrm{a}}$ \\
\hline \multicolumn{2}{l}{ SD. Standard deviation aPaired t-test } & & &
\end{tabular}

was categorized as quite good $(7.40 \%$ and $8.05 \%$ in the control and intervention groups, respectively). This may reflect the role played by the pharmacist at the Kembangan Healthcare Center in West Jakarta during the monthly consultation program. However, another study should be performed with a larger sample size that represents the total population of type 2 DM patients treated at the Kembangan Health Center in West Jakarta. Further research should be conducted to compare the effectiveness of education media by providing drug information and booklet along with other educational media to increase patient adherence.

\section{CONCLUSION}

A booklet can play a key role in improving treatment compliance among patients with type 2 DM. Provision of drug information and booklet were found effective in decreasing $\mathrm{HbA} 1 \mathrm{c}$ level from $8.05 \pm 0.91$ to $6.92 \pm 0.47$ with delta HbA1c $1.13 \pm 0.62$ and helped to increase the treatment adherence among patients with type $2 \mathrm{DM}$ at the Kembangan Health Center, West Jakarta. Therefore, drug information and booklet are effective interventions to increase patients' adherence.

Table 4: Average HbA1c level in control group at week 0 and week 11 according to the level of glycemic control

\begin{tabular}{llllll}
\hline HbA1c level & \multicolumn{2}{l}{ Week 0} & & Week 11 & Delta \\
\cline { 2 - 3 } & Average \pm SD & n (\%) & & Average \pm SD & n (\%) \\
\hline Controlled $(\leq 7)$ & $6.375 \pm 0.18$ & $4(26.66)$ & & $6.5 \pm 0.36$ & $5(33.33)$ \\
Uncontrolled $(>7)$ & $7.90 \pm 0.77$ & $11(73.33)$ & & $8.01 \pm 0.76$ & $10(63.33)$ \\
$\begin{array}{l}\text { Decreased } \\
\text { Consistent }\end{array}$ & & & & $6(40)$ \\
$\begin{array}{l}\text { Increased } \\
\text { Total }\end{array}$ & & & & $3(20)$ \\
\hline
\end{tabular}

HbA1c: Hemoglobin A1c, SD: Standard deviation

Table 5: Average HbA1c level in intervention group at week 0 and week 11 according to the level of glycemic control

\begin{tabular}{|c|c|c|c|c|c|}
\hline \multirow[t]{2}{*}{ HbA1c level } & \multicolumn{2}{|l|}{ Week 0} & \multicolumn{2}{|l|}{ Week 11} & \multirow[t]{2}{*}{ Delta } \\
\hline & Average \pm SD & n (\%) & Average $\pm S D$ & n (\%) & \\
\hline Controlled $(\leq 7)$ & $6.63 \pm 0.35$ & $3(20)$ & $6.48 \pm 0.26$ & $7(46.66)$ & \\
\hline Uncontrolled ( $>7$ ) & $8.40 \pm 0.40$ & $12(80)$ & $7.3 \pm 0.17$ & 8 (53.33) & \\
\hline Decreased & & & & $14(93.33)$ & \\
\hline Consistent & & & & $1(6.67)$ & \\
\hline Increased & & & & - & \\
\hline Total & $8.05 \pm 0.91$ & & $6.92 \pm 0.47$ & - & 1.13 \\
\hline
\end{tabular}

HbA1c: Hemoglobin A1c, SD: Standard deviation

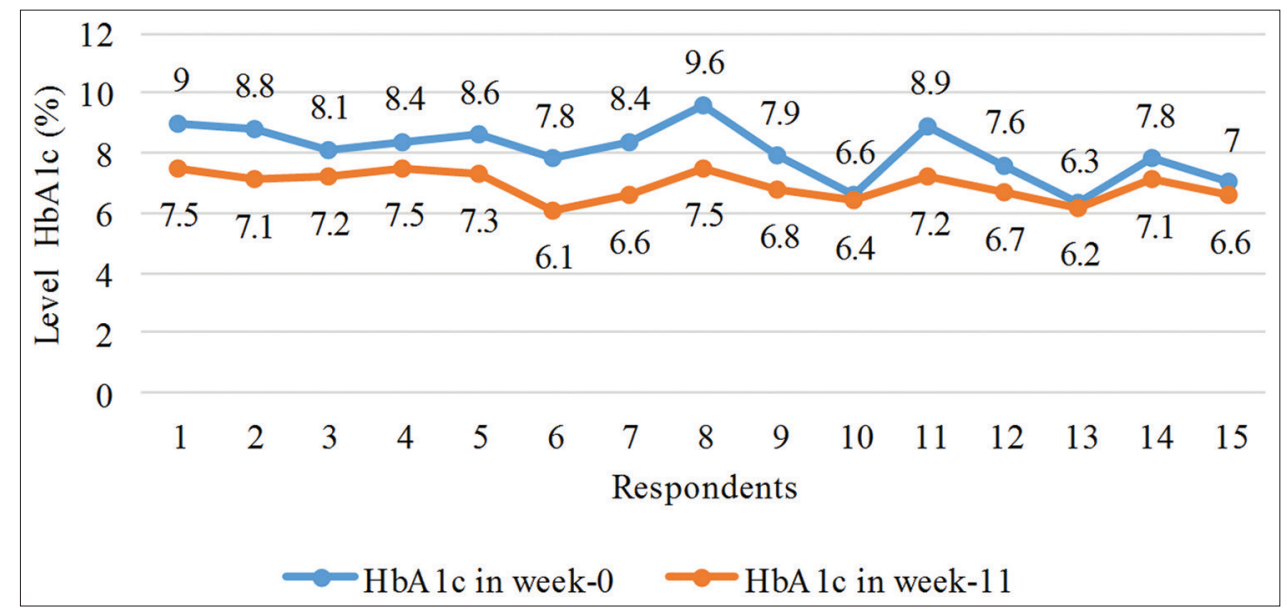

Fig. 3: Pre- and post-intervention hemoglobin A1c levels of individual patients in the intervention group 


\section{CONFLICTS OF INTEREST}

The authors declare that there are no conflicts of interest in this study.

\section{REFERENCES}

1. IDF. Diabetes Atlas. $6^{\text {th }}$ ed. IDF; 2015. Available from: http://www.idf. org/diabetesatlas. [Last accessed on 2017 Mar 25].

2. Adisa R, Fekeye TO, Fasanmade A. Medication adherence among ambulatory patients with Type 2 diabetes in tertiary health care setting in Southwestern Nigeria. Pharm Pract 2011;9:72-81.

3. Perkeni. Consensus on the Management and Prevention of the Type 2 Diabetes Mellitus in Indonesia in 2015. Jakarta: Perkumpulan Endokrinologi Indonesia; 2015.

4. Ghimirey A, Sapkota B, Shrestha S, Basnet N, Shankar PR, Sapkota S, et al. Evaluation of pharmacist counseling in improving knowledge, attitude, and practice in chronic kidney disease patients. SAGE Open Med 2013;1:1-5.

5. Arjona Ferreira JC, Marre M, Barzilai N, Guo H, Golm GT, Sisk CM, et al. Efficacy and safety of sitagliptin versus glipizide in patients with Type 2 diabetes and moderate-to-severe chronic renal insufficiency. Diabetes Care 2013;36:1067-73.

6. Gay EC, Cai Y, Gale SM, Baron A, Cruickshanks KJ, Kostraba JN, et al. Smokers with IDDM experience excess morbidity. The Colorado IDDM registry. Diabetes Care 1992;15:947-52.

7. Morisky DE, Munter P. New medication adherence scale versus pharmacy fill rates in hypertensive seniors. Am J Manag Care 2011;15:59-66.

8. Puspitasari AW. The Effectiveness Analysis of Drug Booklet Presentation on Adherence Level was Evaluated from Hemoglobin Level (HbA1c) and Morisky Medication Adherence Scale (MMAS) -8 in Patients with Type 2 Diabetes Mellitus in Bakti Jaya Health Center. Depok: Universitas Indonesia; 2012

9. Yuniarti D. Evaluate Patient Adherence of type 2 Diabetes Mellitus Through a Booklet that was Followed with the Patient in Beji and Pancoran Mas Health Center. Depok: Universitas Indonesia; 2013.

10. Ministry of Health and National Institute of Health Research and Development. National Report on Basic Health Raesearch, Riskesdas, 2013. Jakarta: NIHRD; 2014.

11. Irawan D. Prevalence and Risk Factors for the Incidence of Type 2 Diabetes Mellitus in Urban Areas of Indonesia. Thesis. Jakarta: Faculty of Public Health, Universitas Indonesia; 2010.
12. Nuryati S, Madanijah S, Atmarita A, Hardinsyah H. Lifestyle and nutirional status and its relationship with diabetes mellitus in adult women in Jakarta. Gizi Indones 2009;32:117.

13. Guariguata L, Whiting DR, Hambleton I, Beagley J, Linnenkamp U, Shaw JE, et al. Global estimates of diabetes prevalence for 2013 and projections for 2035. Diabetes Res Clin Pract 2014;103:137-49.

14. Dipiro JT, Well BG, Schwinghhammer TL, dan Dipiro CV. Pharmacotherapy Handbook. $7^{\text {th }}$ ed. USA: McGraw-Hill; 2015. p. 210-26.

15. Presetiawati. Analysis of the Effectiveness of Giving Counceling and Leaflet to the Decrease of the HbA1c Type 2 Diabetes Mellitus Patient. Jakarta: Kabupaten Lebak; 2014.

16. World Health Organization. Adherence to Long-Term Therapies: Evidence for Action. Geneva: World Health Organization; 2003.

17. Keban AJ. Evaluation of pharmacist educational outcome in patients with Type 2 diabetes mellitus in Dr. Sardjito Hospital, Yogyakarta. J Ilmu Kefarmasian Indones 2013;11:52-3.

18. Waspadji S. Diabetes Mellitus, Chronic Complications and Prevention. Jakarta: FKUI; 2013

19. Suh DC, Choi IS, Plauschinat C, Kwon J, Baron M. Impact of comorbid conditions and race/ethnicity on glycemic control among the US population with Type 2 diabetes, 1988-1994 to 1999-2004. J Diabetes Complications 2010;24:382-91.

20. Battino M, Bompadre S, Politi A, Fioroni M, Rubini C, Bullon P, et al. Antioxidant status (CoQ10 and vit. E levels) and immunohistochemical analysis of soft tissues in periodontal diseases. Biofactors 2005;25:213-7.

21. Sullivan SD, Dalal MR, Burke JP. The impact of diabetes counseling and education: Clinical and cost outcomes from a large population of US managed care patients with Type 2 diabetes. Diabetes Educ 2013;39:523-31.

22. McCord AD. Clinical impact of a pharmacist-managed diabetes mellitus drug therapy management service. Pharmacotherapy 2006;26:248-53.

23. Nishita C, Cardazone G, Uehara DL, Tom T. Empowered diabetes management: Life coaching and pharmacist counseling for employed adults with diabetes. Health Educ Behav 2013;40:581-91.

24. Suppapitiporn S, Chindavijak B, Onsanit S. Effect of diabetes drug counseling by pharmacist, diabetic disease booklet and special medication containers on glycemic control of Type 2 diabetes mellitus: A randomized controlled trial. J Med Assoc Thai 2005;88 Suppl 4:S134-41. 